\title{
WALT WHITMAN AND LOUIS SULLIVAN: The Aesthetics of Egalitarianism
}

KEVIN MURPHY

ONE OF THE CURIOUS anomalies in the history of modern architecture is that Louis Sullivan, the man generally regarded as the Father of Functionalist Architecture, was himself a practicing ornamentalist, and, if anything, in terms of practice, his ornament may be his primary contribution to architecture. The source of the confusion lies in the fact that Sullivan wrote extensively on architecture, and his catch phrase, "form ever follows function," is irrevocably associated with his work. This position, however, becomes problematic as soon as one looks at the buildings. On the one hand, both the Wainwright (St. Louis, 1890) and the Guaranty (Buffalo, 1895), following the format Sullivan suggested in his essay, "The Tall Office Building Artistically Considered," embody what seem to be the essential elements of functional design (Figs. 1-2). The façades of both buildings illustrate the tripartite functions taking place within: a two-story base devoted to expanded shop windows, a number of stories of uniform office space, and an attic housing the mechanical apparatus necessary to the physical plant. On the other hand, both buildings are covered with ornament, an architectural element anathema to functional design. There has been, of course, a number of attempts to address the question of the place of ornament in Sullivan's larger architectural scheme. ${ }^{1}$ However, all these studies are somewhat diffuse in their efforts to locate the source of Sullivan's peculiar theory of art, other than to say that Sullivan's thinking seems a hodgepodge of positivist, evolutionist, Nietzschean, and poetic sources and that his writings on the subject are abstract, inflated, and self-indulgent. While one would surely have to agree with the pronouncements on Sullivan's prose style, it would be a mistake to dismiss the closely worked-out theory of architecture contained in seminal works such as "The Tall Office Building Artistically Considered" and Kindergarten Chats on the grounds of his overblown rhetoric. What I propose instead is to examine a widely acknowledged source of Sullivan's thinking, the poetry and cultural criticism of Walt Whitman, which he consistently paid homage to throughout his career, and to use that source as a lens with which we might focus Sullivan's writings on architecture. ${ }^{2}$ The central parallel I wish to examine is the extent to which the social and political assumptions of 
the two artists determined the experiments in form which each made in his respective art.

In Whitman's most characteristic poems, such as "Crossing Brooklyn Ferry" and "Song of Myself," the subject of the poem quickly becomes what happens when one reads a poem, with the significance of the poem hinging on reader awareness of and active involvement in this process. Likewise the façades of Sullivan's well-known skyscrapers embody his understanding of what happens when one sees-or more accurately, when one experiences-a building. In both cases, the artist demands a fundamental reconsideration of what art is in terms of what art does with respect to a broader social vision. This vision, shared by Whitman and Sullivan, articulated a radical egalitarianism which must perforce alter fundamentally the relation between the artist and his audience. The reader-oriented poetics of Whitman which resulted from this embrace of egalitarianism provides an illuminating entry into Sullivan's architectonics, one with which we might better understand the "function" of Sullivan's ornamentation in his user/observer-oriented theory of architecture.

In an adulatory letter written to Whitman shortly after he had received final approval of his proposals for the Auditorium Building, the young Sullivan confessed to the aging poet that his orbit "responded to the new attracting sun" and sought Whitman's advice and understanding. ${ }^{3}$ Even though Whitman apparently did not respond, his influence continued to exert a strong pull long after this one-way exchange. Sullivan's subsequent prose works are filled with direct citations from Whitman's poems and, equally significantly, with specific allusions to the terminology Whitman used in his cultural and poetic criticism. What attracted Sullivan to Whitman was something that went beyond the appeal and the innovation of individual poems; it was Whitman's insistence on seeing his poetic experimentation in a larger social and political context, a context which would both clarify and necessitate his radical departure from tradition.

The central question Whitman posed for himself throughout his poetic career was one which Sullivan would later apply to the field of architecture: how should poetry, produced under the distinctly new political, social, and cultural conditions of America, differ in substance and kind from poetry of earlier times? Whitman, in response as a radical democrat, proposed new definitions of both poets and poetry.

For Whitman, poetry was essentially a public act, or at least one in which direct address to the audience was an essential element of what constituted poetry. Rather than isolating the poet from the people and experiences he or she is to represent, Whitman insists that "the proof of a poet is that his country absorbs him as affectionately as he has absorbed it."4 Even more, in place of the poet as either elite intelligence or social outcast, Whitman says, "The great master has nothing to do with miracles. He sees health for himself in being one of the mass.... He sees the hiatus in singular eminence. To the 
perfect shape comes common ground" (367-370). The common ground Whitman refers to, of course, is the work of art, an experience which would unite rather than isolate the artist and his or her audience. Thus, Whitman goes on to describe the poet as "the common referee," the "equable man," and the "equalizer of his age and land" (120-125). And, if there were any doubt left on the subject, Whitman adds, "The poet sees for a certainty how one not a great artist may be just as sacred as the great artist" (152-153). In his embrace of democracy, Whitman wishes to obliterate the distinctions between artist and non-artist. In the act of the poem, Whitman wishes to construct a horizontal plane upon which the artist and his audience exist in radical equality.

Behind these pronouncements stands an imposition of the political ideals of a democracy upon the aesthetic continuum existing between an artist and his audience. Whitman's original hypothesis, "The United States themselves are essentially the greatest poem" (11-12), allows him to explore simultaneously a double aspect implicit in his equation: Americans as constituent members of a political union and a poetic fiction. What is true of the one must, or should, be true of the other. The central question of course is what this means in terms of the actual writing and reading of poetry.

While one may find many remarks on this subject scattered throughout the Prefaces Whitman wrote for the different editions of Leaves of Grass as he expanded the original volume, Whitman's most extensive meditation on this issue came in the wake of the Civil War, the traumatic watershed in American cultural history which caused him to reexamine many of his earlier optimistic assumptions, both political and poetic, about what was possible in America. Democratic Vistas, the lengthy essay which resulted from this reexamination, is a strange combination of political diatribe and literary analysis, very reminiscent of the interlaced architectural and cultural criticism one finds in Sullivan. And yet it is also, despite its inflated rhetoric and sometimes meandering narrative, what Lewis Mumford has called "still the most fundamental piece of literary and social criticism written in America."5 While a close analysis of Whitman's entire argument would require a separate study in its own right, one can point out that the essay hinges on the distinction Whitman draws between "feudalism" and "democracy," terms which Sullivan carries over complete into his architectural writings, especially Kindergarten Chats and Natural Thinking.

In essence, for Whitman the term "feudalism" encompassed all previous cultural systems which encouraged hierarchies, that is, the placing of one individual over another. Thus the Church, the orders of nobility, even the Army and Navy with their systems of rank were inevitably "feudal" in their make-up. What was also evident for Whitman was that, even though America had, with its Declaration of Independence and Constitution, abstractly declared itself opposed to such hierarchies, in terms of day-to-day mores, America remained in the grip of feudal thinking. For Whitman, "democracy" 
was the antithesis of such thinking. It was instead a cultural system which would replace the vertical make-up of feudalism which emphasized only the exemplary individual with a horizontal one which emphasized simultaneously both the potentiality of individualism and the interconnectedness of all members of society. Therefore, Whitman, rather than praise great men, as had the poetry of the past, offers instead the central axiom, "The average man of a land at last only is important." 6 Whitman recognized that this radical egalitarianism had "few or no full realizers and believers" (844-845), and, as a result, America continued to perpetuate the inequalities of previous "feudal" cultures, even though it espoused democratic values.

Whitman's central point which follows is that the great bridge needed to span the abyss between the abstract principles supposedly governing America and the actual day-to-day experiences of average Americans is a body of democratic literature. In short, it was necessary to create a democratic culture. Whitman therefore calls for the development of a class of American authors - as Sullivan would later call for a similar class of architects - whose ultimate result, after inspiring other teachers, manners, and schools of thought, would be nothing short of a cultural revolution. But, even more important in terms of the kind of literature this revolution should produce, Whitman turns to a consideration of literary form and offers a startling theory of participatory aesthetics:

a new theory of literary composition for imaginative works of the very first class, and especially for highest poems, is the sole course open to these States. Books are to be call'd for, and supplied, on the assumption that the process of reading is not a half-sleep, but, in highest sense, an exercise, a gymnast's struggle; that the reader is to do something for himself, must be on the alert, must himself or herself construct indeed the poem, argument, history, metaphysical essay - the text furnishing the hints, the clue, the start or frame-work. Not the book needs so much to be the complete thing, but the reader of the book does. That were to make a nation of supple and athletic minds, well-train'd, intuitive, used to depend on themselves, and not a few coteries of writers. (1955-1966)

Earlier in the essay, Whitman had insisted that citizens participate in the political process of democracy; so too he here insists that readers participate in the poetic creation of its imaginative counterpart. Even the metaphors he uses are identical: "Political democracy," he insists earlier, "supplies a training-school for making first-class men. It is life's gymnasium" (715-717). The gymnast's struggle of the poem becomes a direct analogue of the political struggle for equality.

In this light, Whitman's obliteration of the distinction between the artist and his audience becomes much more intelligible. Rather than declare in an outburst of democratic enthusiasm that everyone is an artist, Whitman means to lay a serious task before his readers, but a task which they, given Whitman's optimistic view of their potential, should be equal to. With "the hints, the clue, the start or framework" of the poem before him, the reader 
must equate his powers of poetic imagination with those of the author and create collectively with him the New World of the poem. In his "gymnast's struggle" with the text, the reader develops his imaginative powers and thereby achieves the "high average of men" (1029), the egalitarian standard with which Whitman means to displace Old World standards of literature. In this broader social context, the function of poetry is both the elevation and equalization of its audience. In terms of the work of art itself, then, a necessary implication of this prescription is a shifting of the plane of aesthetic significance from the work of art to the eye of the beholder.

This ideological orientation clarifies at least two of the salient characteristics of Whitman's best poetry: the extended catalogues of perceptual or imaginative experiences that constitute the substance of his longer poems and the direct address of the reader throughout the poems, guiding and explicating his response to the profusion of the catalogues. The poems, quite literally imaginative exercises, have as their function the strengthening of the reader's power and awareness of imaginative absorption and identification. Even more characteristic is Whitman's insistence throughout his poetry that "what I assume you shall assume." Again and again, in the midst of his perceptual litanies, the speaker will return to guide and encourage the reader's response, making a poem like "Song of Myself" or "Crossing Brooklyn Ferry" as much a handbook on how to read this new form of poetry as it is a celebration of the speaker's experience. The egalitarian orientation of Whitman's aesthetics provides the rationale for this experimentation and emphasizes the necessity of reader involvement in the shaping of the poem's coherence. ${ }^{7}$

When one turns to Sullivan's writings on architecture later in the century, Whitman's influence seems everywhere. In many ways, one could easily read Kindergarten Chats, Sullivan's major written work, as his transposition of "Song of Myself" into prose. Aside from numerous citations of Whitman's poetry in the work and the organizational parallel (both works are divided into fifty-two sequential, accumulative sections), they have a variety of more subtle echoes in which Kindergarten Chats deftly reinstates both the concerns and the strategies of Whitman's major work. Both works, for example, focus on a teacher guiding a student or initiate; both review contemporary life; both insist on a fundamental reexamination of the origins and practice of the art form in question; both share an "indirect" method in which the guide only points to the issues at hand while the initiate must draw conclusions for himself. More importantly, the analysis of contemporary architecture which Sullivan presents draws extensively on the cultural analysis which Whitman made earlier in the century, right down to the distinctions Whitman drew between "feudal" and "democratic" culture.

What we discover throughout Sullivan's writings is that, as Whitman had suggested about the analysis of poetry, the analysis of architecture is in fact synonymous with the analysis of the social fabric of a people. As Sullivan 
says at the outset of Kindergarten Chats, "by this light, the critical study of architecture becomes not merely the direct study of an art-for that is but a minor phase of a great phenomenon-but, in extenso, a study of the social conditions producing it; the study of a newly-shaping type of civilization."8 What is equally revealing, however, is the striking parallel Sullivan posits between poetry and architecture in his revelation of the social basis of buildings. From the very first, the teacher in Kindergarten Chats uses the language of literature and literary analysis to approach the study of architecture, and it is this language which is so problematic for the young architecture student whom the teacher is initiating. When the teacher says, for example, "Every building tells its story, tells it plainly," the student objects, "I can never learn to do this. I feel that it requires the eye of a poet." The teacher replies with the affirmation, "Never fear. We are all poets," a remark which at first seems distinguished only by its naiveté.

However, the assumption Sullivan is making here is an important one, one upon which his theory of architecture hinges. As he says in another context, "If it is assumed that the art of reading is confined to the printed page, we cannot go far. But if we broaden and quicken our sense of reading until it appears to us, in its more vital aspect, as a science, an art of interpretation, we shall go far indeed." Sullivan goes on, in a very Whitmanesque vein, to extend this capacity for visual interpretation to the average man, the ideal reader in Whitman's egalitarian aesthetics. What he says is worth quoting at length, since it aligns Sullivan not only with Whitman's political thinking but also with his reader-oriented aesthetics:

Indeed, most of us have, in less or greater measure, this gift of reading things. We come into it naturally; but, curiously enough, many are ashamed because it does not bear the official stamp of that much misunderstood word, scholarship, a stamp, by the way, which gives currency to most of the notions antagonistic to the development of our common, thinking powers. It is this same scholastic fetichism, too, that has caused an illogical gap between the theoretical and the practical. In right thinking such gap cannot exist. A true method of education, therefore, should consist in a careful and complete development of our common and natural powers of thinking, which, in reality, are vastly greater, infinitely more susceptible to development than is generally assumed. Indeed, the contumacy in which we habitually underrate the latent powers of the average human mind is greatly to our discredit. It constitutes, in fact, a superstition. A superstition whose origin is readily traceable to the scholasticism of past centuries, and to the tenacious notion of social caste. It is definitely the opposite of the modern and enlightened view now steadily gaining ground, that the true spirit of democratic education consists in searching out, liberating, and developing the splendid but obscured powers of the average man, and particularly those of his children. ${ }^{10}$

From this point of view, we can understand more clearly why the entire progression of Kindergarten Chats, a book Sullivan explicitly aimed at a lay audience, is in a very real sense the instruction of the student in the art of reading buildings. And since this instruction advocates an analysis which is simultaneously social and lyrical, the guide, in much the same fashion as the 
speaker in Whitman's "Song of Myself," must of necessity reconsider the fundamental ground of the art form which he is surveying.

As an elementary method of calling the student's attention to the design of the buildings around him, the teacher offers a "functional" analysis of what were then the accepted and revered models of architecture. As he says, debunking the Marshall Field Store, "Surely if it were a department store, all masonry would be reduced to a minimum, and there would be an expanse of glass for light and display." 11 But, as the teacher progresses in his instruction, he moves much beyond this utilitarian functionalism to speak of the Art of Expression as the culmination of architecture.

Before he can address this issue, though, he instructs his initiate in the origins of the art of architecture, origins which he reduces to the three fundamental elements of pier, lintel, and arch. The pier is the simplest element of architecture, so the teachers says, because it contains within it the primal forces of aspiration and compression, forces the teacher associates with the Rhythm of Life and the Rhythm of Death. These antagonistic and dialectical forces are the fundamental link between the human and the natural worlds, between the subjective and the objective, the source of the "innumerable rhythms born of them, exterior to man and within him." Even more, he says, the pier "is in equilibrium - at seeming rest. While it seems aspiring, it seems also solidly founded: it impresses us as immovable, as static: as timeless. Simple as it seems and is to our sense of sight, it is nevertheless compound; for it is the field of operation of two synchronous forces-downward and upward." The lintel, on the other hand, is without function until it is attached to the pier. When it is attached, however, "architecture springs into being not only as a science, and a useful art, but also as an art of expression." When the teacher turns to the third element of architecture, he becomes most metaphoric and humanistic:

More subtle, more intricate, more subjective than either pier or lintel, the arch has so much more of man in it. We may therefore view it both as a triumph over an abyss and as the very crystallization of that abyss itself. It is a form so much against Fate, that Fate, as we say, ever most relentlessly seeks its destruction. Yet it does rise in power so graciously, floating through the air from abutment to abutment, that it seems ever, to me, a symbol and epitome of our own ephemeral span. ${ }^{12}$

For Sullivan, then, we see that architecture literally embodies the character of human life. The elements of architecture are parallel to the aspiration, duration, and limitation of human life; in short, the span of architecture replicates the span of life. The initiate, in response to this instruction, says that he now understands the anthropomorphic and humanistic core of words like "subjective" and "objective" and, even more, now understands what the teacher means by such words as "form" and "function" and "power." Simply put, man "recreates himself in what he does," and the function of architecture is to express the dialectic of human aspiration and limitation in architec- 
tural form. But since, as the teacher will say in another section, the real function of architecture is to interpret and initiate social change, an equally important function of architecture is to impress that humanistic idea, that balanced tension, upon an observer, one presumably drawn from the great average of mankind.

With these objectives in mind, we should see that Sullivan's catch phrase, "form ever follows function," has to be seriously revised, or more accurately amplified, to take into account this observer-orientation. "Function" must refer not only to what is taking place inside the building but also to what is taking place inside the mind of the observer. The utility or use of a building is only the beginning. Given Sullivan's social and political assumptions, a primary function of an architectural entity is to establish connection with the observer, not to replace the historical associative model of classical forms with a contemporary associative model of utilitarian coding. The impact of a building - that is, its connection with an observer-must be established in terms of an integration of visual movements into a unified wholenot simply a bald denotation of mechanical use.

To illustrate this aesthetic, we return to the façade of the Guaranty building (Fig. 2). I choose this building since, in terms of the traditional understanding of Sullivan's functionalism, it is the most paradoxical since it is the most ornamented of his skyscrapers. The façade is entirely covered with a highly ornamented terra cotta, which, in terms of the utilitarian functions taking place within the building, is completely irrelevant. Those functions, as Sullivan indicates in his essay, are clearly demonstrated in structural differentiation. But it is the ornamentation which, together with the structural elements, impresses upon the observer that tension of opposites which Sullivan saw as the central rhythm of a building. Given the ornamentation, the piers, as Vincent Scully suggests, appear as "released springs" (Fig. 3) which emphasize the vertical ascension of the building which rises to the overhanging cornice and, at the oculi, turns back to earth. ${ }^{13}$ Observed from ground level (Fig. 4), the oculi lean out to complete the arch of the pier-andmullion upward thrust and return it back to ground level, thus integrating the upward and downward thrust of the ornamented façade. The columns which support the building at its base, on the other hand, with their narrow horizontal bands, emphasize the physical compression weighing down from the building above. Even here, however (Fig. 5), the gradual narrowing of the window spaces from the wide shop window at ground level to the centered second-floor window to the mullion which leaps upward replicating the upward movement of the piers provides a counterbalance to the compression expressed in the horizontal banding of the columns. Between these two crucial areas of counterpoised ascension and compression, the stretched diamond banding around the base, especially on the second floor, indicates the collision and fusion of the vertical and horizontal forces embodied in the building. Given this fusion of dialectical forces, the impact points of the op- 


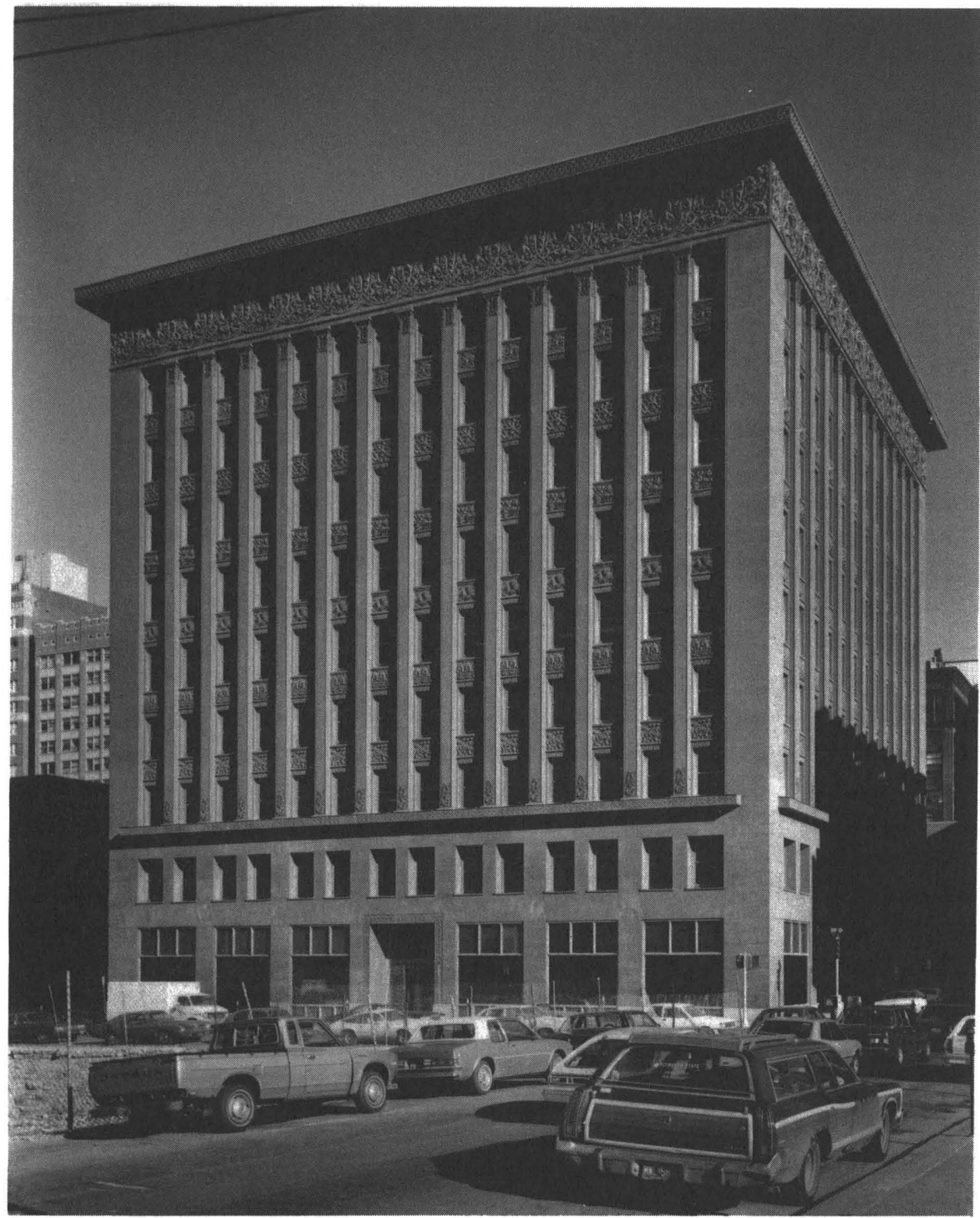

Fig. 1 The Wainwright Building, Saint Louis. Photograph by Cervin Robinson.

posing forces are left paradoxically yet appropriately nude (Fig. 6), as if at these points of maximum compression the building's structure erupts through the skin of ornamentation. Thus, at all three levels of exterior design mandated by different utilitarian function, there are translated into visual analogues to be imprinted on the observer the compressive (bearing) function of the vertical columns against the tensile (spanning) function of the horizontal beams. ${ }^{14}$ But this translation is one that is accomplished metaphori- 


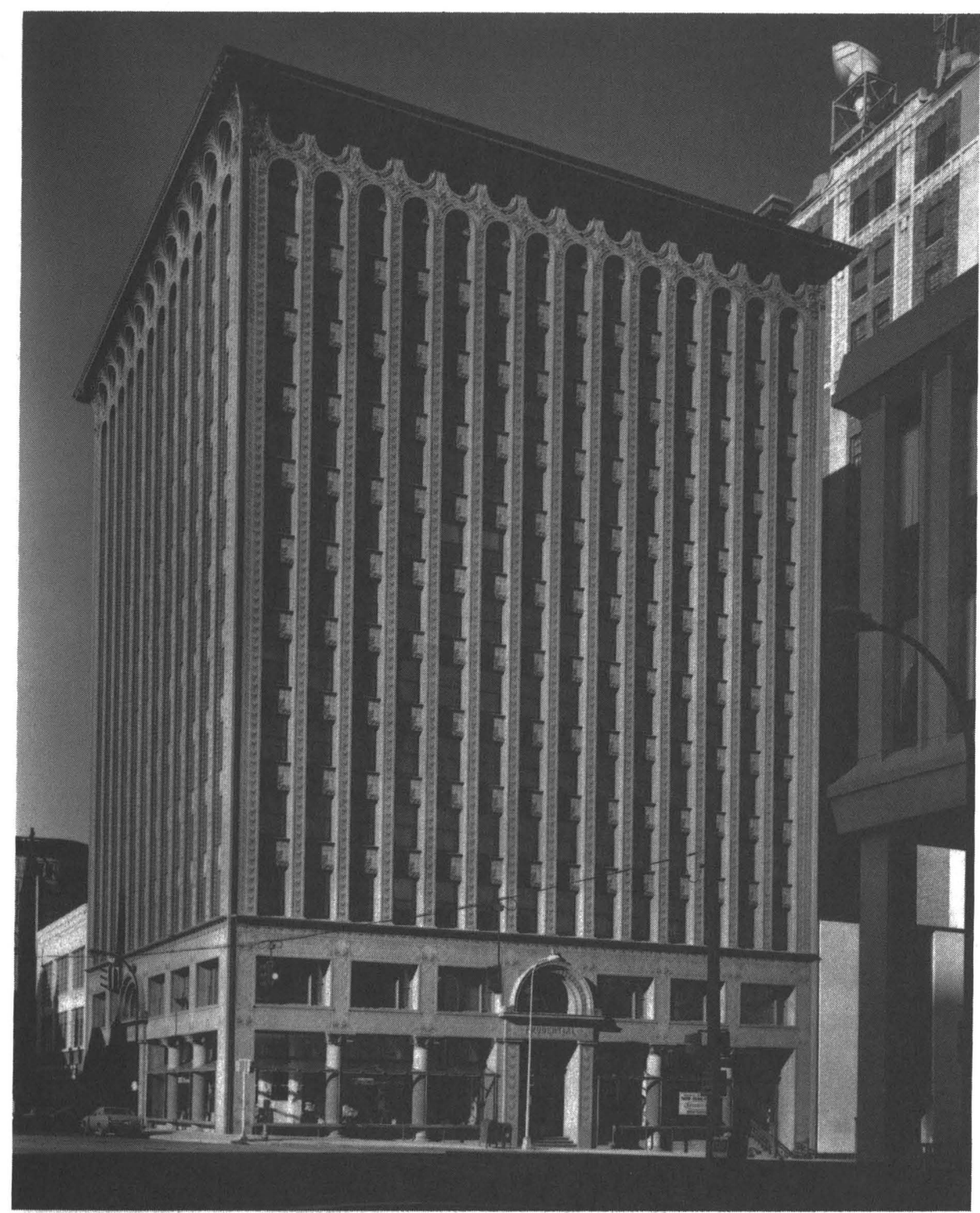

Fig. 2 The Guaranty Building, Buffalo. Photograph by Cervin Robinson.

cally rather than literally. It is the manipulation of the ornamentation and the organization of space which imprint these impressions on an observer, and not the exterior manifestation of an interior utilitarian function. The "function" of the ornament, then, is to implicate the observer in the meaning and the aspiration of the building.

Returning to our analogy with Whitman, we can see that the many references and suggestions Whitman makes to his readers in the course of such 


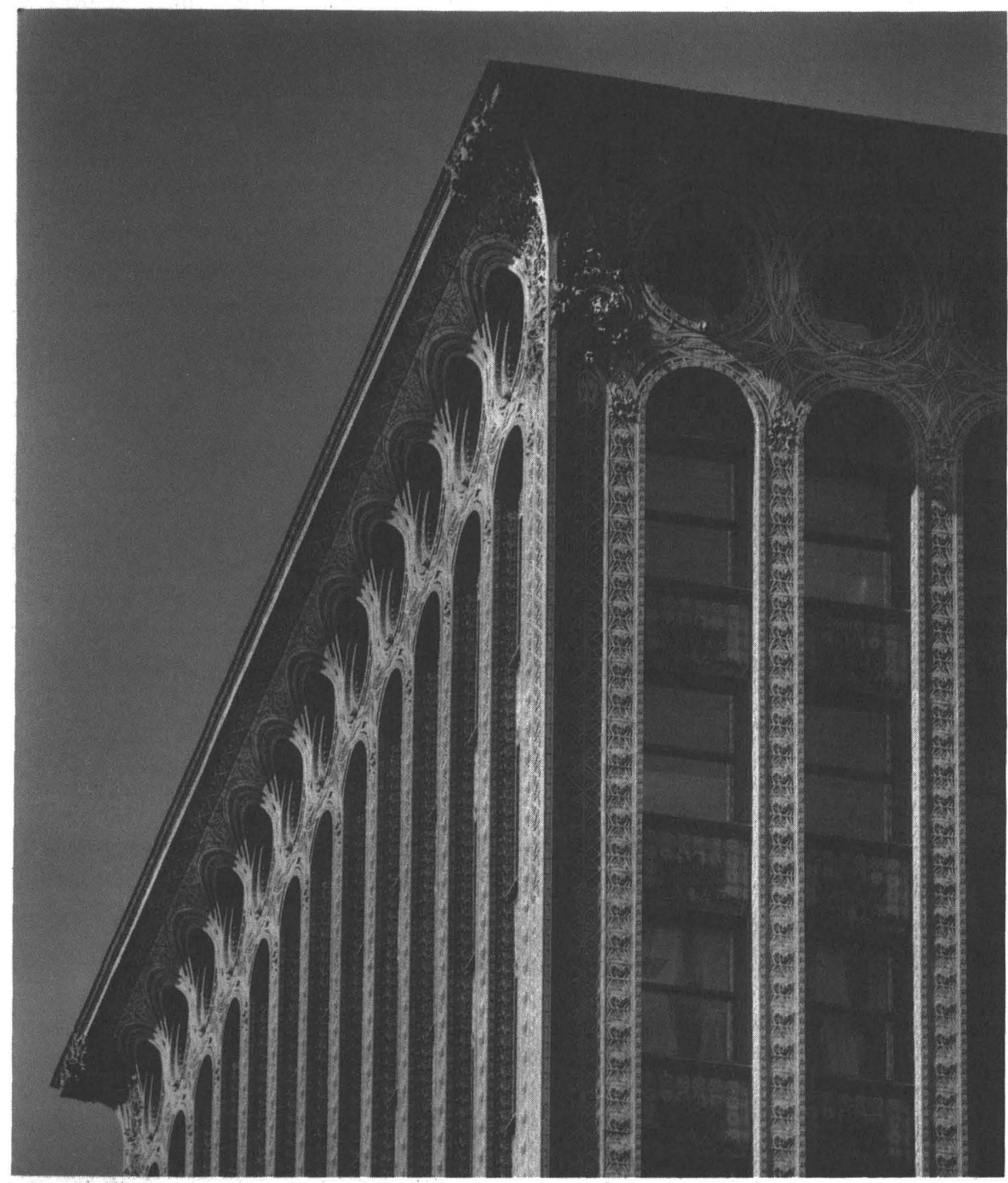

Fig. 3 The Guaranty Building, Upper façade, detail. Photograph by Cervin Robinson.

poems as "Song of Myself" and "Crossing Brooklyn Ferry" illustrate that the poem (and by analogy the building) is as much a meditation on the nature of what poetry (and architecture) does as it is an occasion for expressing a particular narrative (or fulfilling a particular utilitarian or commercial need). The point of the experimentation in both cases is an ideological need to implicate the reader or observer in the creation of meaning. Whitman, more than any other poet of the nineteenth century, believed that poetry was, and 


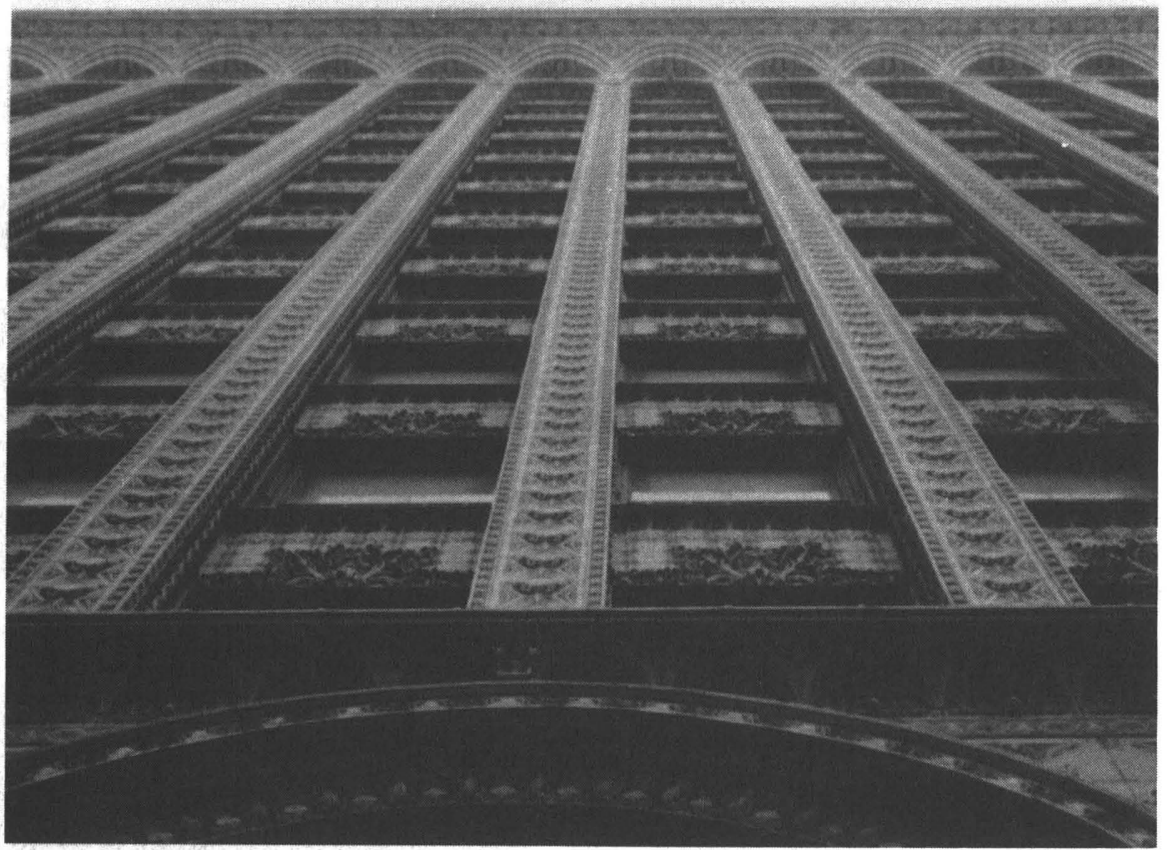

Fig. 4 The Guaranty Building, façade from sidewalk. Photograph by the author.

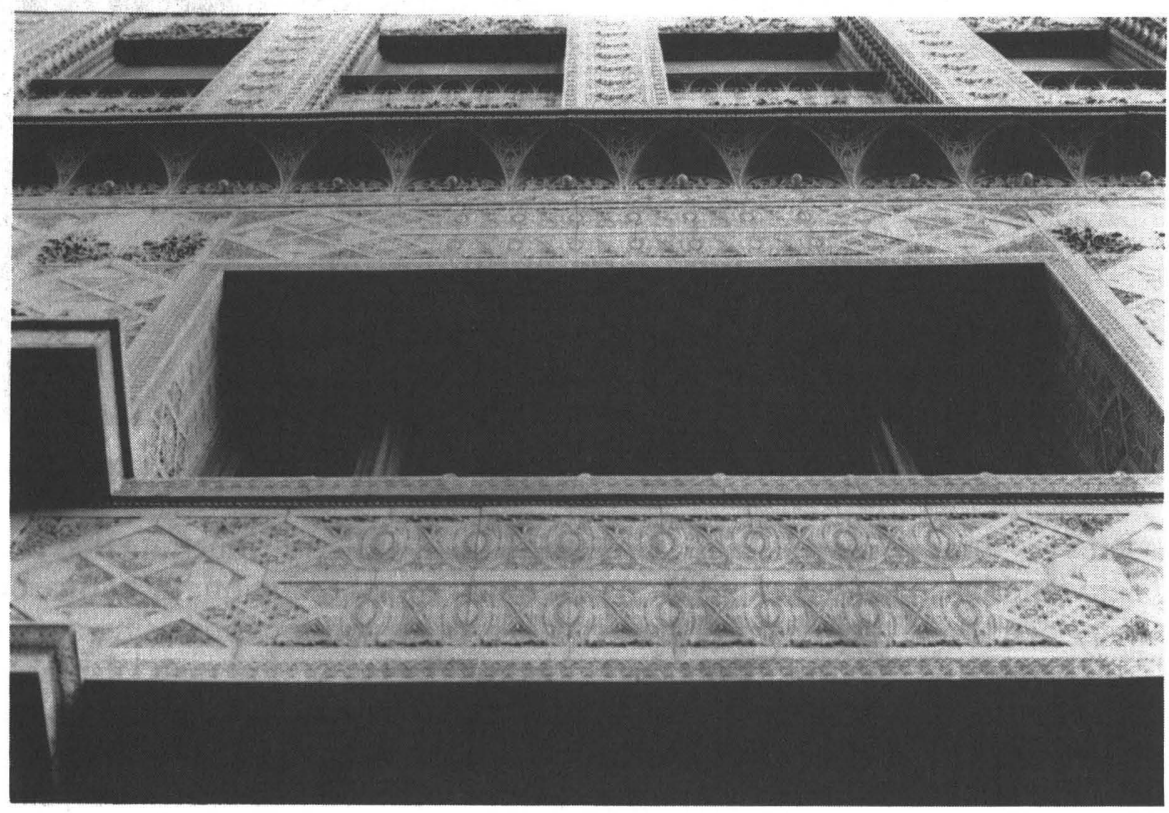

Fig. 5 The Guaranty Building, lower façade, detail. Photograph by Richard Putney. 


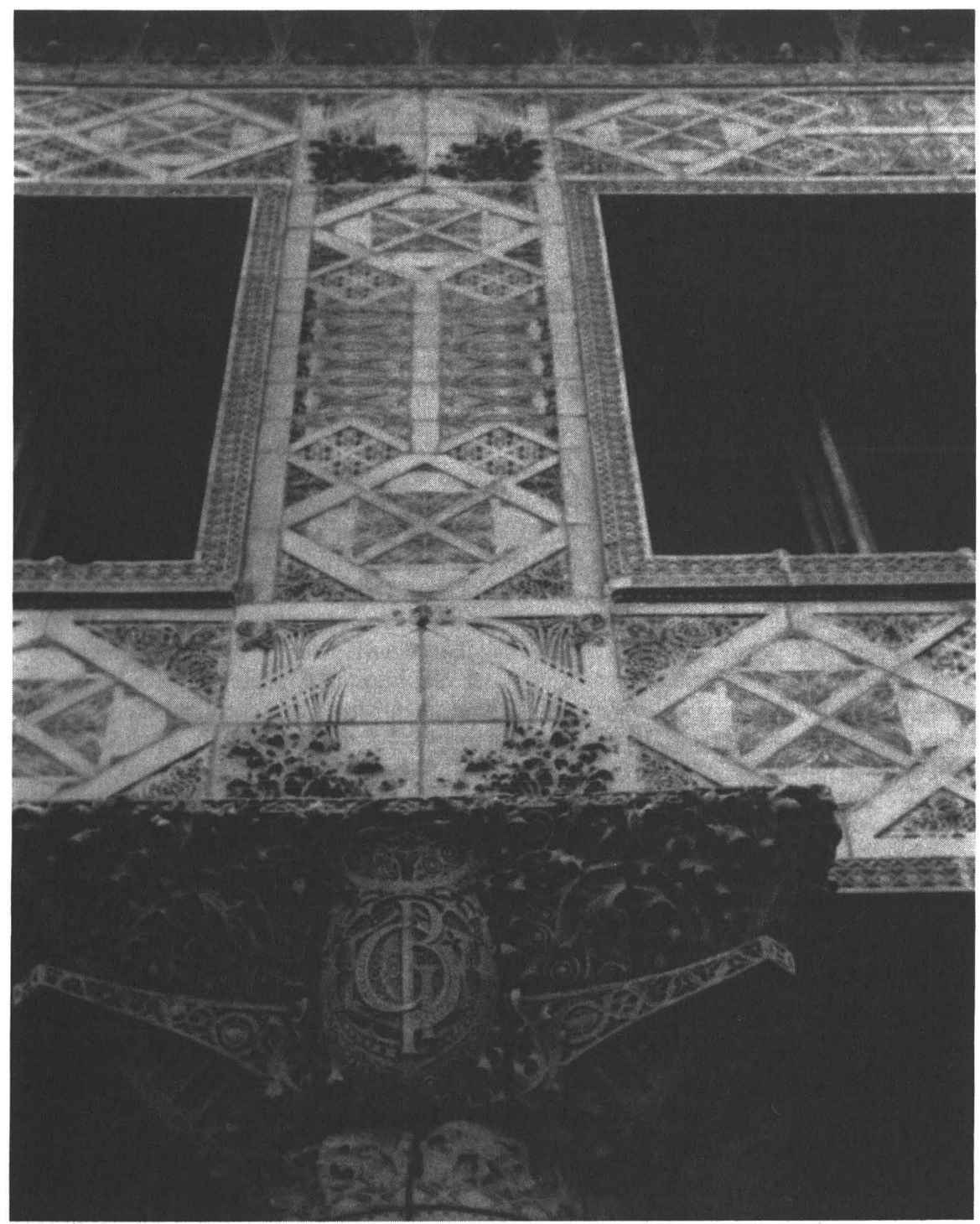

Fig. 6 The Guaranty Building, second story, detail. Photograph by the author.

should be, preeminently a public and social art. As it happens, commercial architecture is the public art which doubtless most affects average people. By concentrating his artistic force on as public and as now commonplace an entity as the commercial skyscraper, Sullivan was elevating the purpose of commercial building to that of monumental architecture, that is, to the level of an architecture which seeks to embody the aspirations of a people and to inspire 
that public with its own best image of itself. Even more, he was extending the province of art into the experience of everyday life, a position totally consistent with the ideology of art advocated by Whitman.

\section{Ithaca College}

\section{NOTES}

1 Narcisco Menocal's Architecture as Nature: The Transcendentalist Idea of Louis Sullivan (Madison: University of Wisconsin Press, 1981) provides the most comprehensive examination of Sullivan's sources, while the chapter on Sullivan in William Jordy's American Architects and Their Buildings (Garden City, New York: Doubleday and Company, Inc., 1972), volume 3, examines the progression of Sullivan's use of ornament in detail. Robert Twombly's recent Louis Sullivan: His Life and Work (New York: Viking, 1986), focuses for the most part on Sullivan's biography but has several analyses of Sullivan's ornament, particularly that of the Guaranty Building. Any study of Sullivan's ornament would of course take into account Vincent Scully's groundbreaking essay, "Louis Sullivan's Architectural Ornament: A Brief Note Concerning Humanist Design in the Age of Force," Perspecta 5 (1959), 73-80, as well as Paul E. Sprague's unpublished dissertation, "The Architectural Ornament of Louis Sullivan and His Chief Draftsmen" (Ph.D. Dissertation, Princeton University, 1969). David Andrew's Louis Sullivan and the Polemics of Modern Architecture (Chicago: University of Illinois Press, 1985) presents a rather dour view of Sullivan's architectural philosophy, while the more recent catalogue accompanying the exhibition of Sullivan's ornament which has recently toured the country, Louis Sullivan: The Function of Ornament (New York: Norton, 1986), provides a more comprehensive and persuasive view of Sullivan's achievement, particularly William Jordy's essay on Sullivan's tall buildings. I also wish to thank Ted Brown for numerous suggestions concerning Louis Sullivan's architectural and social vision.

2 While almost every study of Louis Sullivan's thinking acknowledges his debt to Whitman, of particular importance is Sherman Paul's Louis Sullivan: An Architect of American Thought (Englewood Cliffs, NJ: Prentice Hall, 1962). More recently, Lauren S. Weingarden has traced attitudes toward technology in the writings of Emerson, Whitman, and Sullivan in her "Naturalized Technology: Louis H. Sullivan's Whitmanesque Skyscrapers," Centennial Review 30 (Fall 1986), 480-495. A work which examines the cultural and social context in which Sullivan thrived is Hugh D. Duncan's Culture and Democracy: The Struggle for Form in Society and Architecture in Chicago in the Middle West During the Life and Times of Louis Sullivan (Towana, NJ: Bedminister, 1965).

3 The letter is quoted in its entirety in Sherman Paul's Louis Sullivan, 3-4.

4 See the Preface to the 1855 edition of Leaves of Grass contained in Leaves of Grass: Comprehensive Reader's Edition, ed. Harold W. Blodgett and Sculley Bradley (New York: New York University Press, 1965), 729. All subsequent quotes from the Preface will be cited by line number referring to this standard edition and will be included parenthetically in the text.

5 The Brown Decades (1931; New York: Dover Press, 1971 ed.), 10.

6 The full text of Democratic Vistas is contained in The Collected Writing of Walt Whitman: Prose Works 1892, ed. Floyd Stovall (New York: New York University Press, 1964), 2:387. All subsequent quotations of Democratic Vistas will be cited by line number referring to this standard edition and will be included parenthetically in the text. 
7 I have examined this issue in much greater detail in my thesis, "Poetics of the New World: A Study of Walt Whitman's 'Song of Myself' " (Ph.D. Dissertation, University of Rochester, 1975).

8 Kindergarten Chats and Other Writings, ed. Isabella Athey (New York: George Wittenbarn, Inc., 1947), 24.

9 Kindergarten Chats, 24.

10 "What is Architecture?" in Kindergarten Chats and Other Writings, 230-231.

11 Kindergarten Chats, 27.

12 Kindergarten Chats, 121-124.

13 "Louis Sullivan's Architectural Ornament: A Brief Note Concerning Humanist Design in the Age of Force," Perspecta 5 (1959), 75.

14 See William Jordy's analysis of Sullivan's ornament in American Buildings and Their Architects, volume 3 . 